\title{
Acidified Activated Carbon with Enhanced Electrochemical Performance for Supercapacitors
}

\author{
Bangmin Gao, Yan Li, Yan Tian, and Ligang Gai* \\ Institute of Advanced Energy Materials and Chemistry, School of Chemistry and Pharmaceutical \\ Engineering, Qilu University of Technology, Jinan 250353, People's Republic of China \\ EE-mail: liganggai@qlu.edu.cn
}

doi: $10.20964 / 2017.01 .61$

Received: 2 November 2016 / Accepted: 29 November 2016 / Published: 12 December 2016

\begin{abstract}
Activated carbons carrying oxygen functional groups have been subjected to extensive research due to their potential applications in adsorption, sensors, catalysis, drug delivery, and energy storage/conversion systems. In this paper, acidified activated carbon (AAC) has been prepared through chemical oxidation of commercial activated carbon (AC) in a mild oxidation environment, providing AAC with enhanced concentration of single-graphene layers, improved degree of graphitization, reduced specific surface area and micropore volume, and a surface dominated by $\mathrm{C}=\mathrm{O} / \mathrm{C}-\mathrm{O}$ groups. The electrochemical performance of AC and AAC is investigated in the role of electrode materials for supercapacitors in a three-electrode mode. Compared with AC, AAC exhibits an enlarged working potential window and superior electrochemical performance at current densities lower than $10 \mathrm{~A} \mathrm{~g}^{-1}$. After 5000 cycles at $1 \mathrm{~A} \mathrm{~g} \mathrm{~g}^{-1}$, the specific capacity of AAC is retained at $126.7 \mathrm{~F} \mathrm{~g}^{-1}$, higher than that of $113.7 \mathrm{~F} \mathrm{~g}^{-1}$ for $\mathrm{AC}$.
\end{abstract}

Keywords: Acidified activated carbon; Chemical oxidation; Oxygen-containing functional groups; Electrode materials; Supercapacitors

\section{FULL TEXT}

(C) 2017 The Authors. Published by ESG (www.electrochemsci.org). This article is an open access article distributed under the terms and conditions of the Creative Commons Attribution license (http://creativecommons.org/licenses/by/4.0/). 